\title{
PENGARUH KUALITAS PELAYANAN TERHADAP KEPUASAN PELANGGAN PADA KLINIK HEWAN DI INDONESIA
}

\author{
Eri Sadewo ${ }^{1}$, Farli Humala Siregar ${ }^{2}$, Iwan Sukirna ${ }^{3 *}$, Juda Adisusanto ${ }^{4}$, Nova Fauzan ${ }^{5}$ \\ 1,2,3,4,5 Program Magister Manajemen Stratejik, Universitas Prasetiya Mulya \\ *Corresponding author: iwan.sukirna@student.pmbs.ac.id
}

\section{A R T I C L E I N F O}

\author{
Article History: \\ Revised: 21 April 2021 \\ Accepted: 03 May 2021 \\ Keywords: \\ Klinik Hewan; \\ Kepuasan Pelanggan; \\ Kualitas Layanan.
}

Received: 22 December 2020

\begin{abstract}
A B S T R A C T
Penelitian ini ingin memberikan gambaran terhadap penyedia jasa layanan klinik hewan di Indonesia di tengah pasar yang sangat kompetitif agar dapat menemukan cara untuk mempertahankan pelanggan yang sudah ada dan menarik pelanggan baru. Secara khusus, penelitian ini menguji kualitas pelayanan menggunakan model Service Performance (SERVPERF) dari Cronin dan Taylor yang dikombinasikan dengan akses untuk mendapatkan layanan (access to service) terhadap kepuasan pelanggan pada klinik hewan di Indonesia. Penelitian ini merupakan penelitian kuantitatif menggunakan metode survei terhadap 219 pelanggan yang pernah mengunjungi klinik hewan di Indonesia. Teknik analisis data menggunakan principal component analysis (PCA) dan regresi linier berganda dengan bantuan piranti lunak SPSS. Hasil penelitian menunjukkan bahwa model Service Performance (SERVPERF) yang berpengaruh signifikan terhadap kepuasan pelanggan adalah reliability dan assurance. Sedangkan responsiveness, empathy, tangible ditemukan tidak berpengaruh signifikan terhadap kepuasan pelanggan. Lebih lanjut, penelitian ini menemukan adanya pengaruh positif signifikan variabel akses untuk mendapatkan layanan (access to service) terhadap kepuasan pelanggan. Temuan penelitian ini memberikan kesimpulan bahwa untuk meningkatkan kepuasan pelanggan, maka klinik hewan di Indonesia sebaiknya memberikan perhatian yang lebih terhadap aspek reliability, assurance, dan access to service.
\end{abstract}

\section{Pendahuluan}

Pertumbuhan ekonomi Indonesia terus melaju seiring dengan menguatnya pendapatan per kapita penduduk Indonesia tiap tahunnya tercermin pada tahun 2017 sebesar US\$ 3,877; tahun 2018 sebesar US\$ 3,927 dan tahun 2019 sebesar US\$4,175 (Badan Pusat Statistik, 2020). Bank Dunia memproyeksikan pertumbuhan ekonomi Indonesia terus tumbuh dengan capaian sebesar 5,1\% pada tahun 2020 dan 5,2\% pada tahun 2021 (World Bank, 2019 - Indonesia Economic Quarterly Reports (IEQ)). Indonesia menjadi salah satu negara dengan jumlah hewan peliharaan yang cukup tinggi dan memiliki pasar potensial. Pangsa pasar hewan peliharaan di Indonesia mencapai 15,6\% di Asia Tenggara. Pertumbuhan hewan peliharaan di Indonesia diperkirakan akan mencapai $7,1 \%$ hingga 2020 (http://jakartadoglovers.com).

Laju pertumbuhan ekonomi tersebut memiliki dampak terhadap perubahan gaya hidup masyarakat, salah satunya adalah bertambahnya pemilik hewan peliharaan. Dengan bertambahnya pemilik hewan, tumbuh kesadaran akan pentingnya kesejahteraan 
hewan (animal welfare), serta bertambahnya komunitas pecinta hewan peliharaan (Dassanayake dan Weerasiri, 2017).

Keberadaan klinik hewan memiliki peranan penting untuk memenuhi kebutuhan akan kesehatan dan kesejahteraan hewan peliharaannya. Adanya peluang ini menimbulkan tantangan berupa persaingan bisnis yang sangat kompetitif di antara klinik hewan. Strategi untuk dapat berkembang adalah dengan memahami kebutuhan para pelanggan. Hal ini dapat dicapai dengan memberikan tingkat kualitas layanan yang memuaskan (Dassanayake dan Weerasiri, 2017). Definisi kualitas layanan yaitu kemampuan dari penyedia jasa layanan untuk dapat memuaskan pelanggannya secara efisien sehingga berdampak positif bagi kinerja perusahaannya (Duong et al., 2004).

Untuk menilai kualitas layanan bukanlah pekerjaan yang mudah karena layanan memiliki karakter yang unik diantaranya intangible (tidak berwujud), heterogeneous (heterogen), inseparable (tidak dapat dipisahkan) and perishable (cepat berubah), model yang paling popular digunakan adalah Service Performance (SERVPERF) (Rasyida et al., 2016).

Pada penelitian ini untuk menilai kualitas layanan menggunakan pendekatan model SERVPERF dikombinasikan dengan akses untuk mendapatkan layanan. Model ini dianggap cocok digunakan karena hanya fokus meneliti kualitas layananan yang diberikan kepada pemilik hewan peliharaan di klinik hewan (Dassanayake dan Weerasiri, 2017). Dalam penelitian ini juga ditambahkan variabel independen terhadap akses mendapatkan layanan; baik akses terhadap lokasi maupun pelayanan pembayaran yang belum pernah diteliti sebelumnya di jasa layanan klinik hewan. Peneliti mengembangkan penelitian dengan menambahkan aspek lain dari penelitian sebelumnya yang sudah yaitu bahwa cakupan kepuasan pelanggan hanya meliputi responsiveness, empathy, tangible, reliability tangible, dan assurance oleh Dassanayake dan Weerasiri (2017).

Penelitian ini memegang peranan penting dalam memetakan perilaku dan sudut pandang pelanggan dalam memperolah layanan serta perkembangan bisnis klinik hewan. Hal ini terkait adanya perkembangan gaya hidup, moda transportasi, demografi dan inovasi layanan.

\section{Tinjauan Pustaka dan Pengembangan Hipotesis}

Teori tentang kepuasan pelanggan sesuai service quality didefinisikan menurut Bates dan Hoffman (1999), yaitu penilaian pelanggan terhadap proses penyediaan jasa. Dengan demikian pengevaluasian service quality berarti pengevaluasian terhadap proses produksi jasa. Zeithaml et al. (2009) mengemukakan bahwa kepuasan adalah konsep yang jauh lebih luas dari hanya sekedar penilaian kualitas pelayanan, tetapi juga di pengaruhi oleh faktor lainnya. Kepuasan pelanggan dipengaruhi oleh persepsi pelanggan terhadap kualitas pelayanan, kualitas produk, harga, faktor situasi dan faktor pribadi pelanggan.

Ulasan lanjut dari teori ini mencakup literatur dan studi yang berkaitan dengan aspek kualitas layanan dan kepuasan pelanggan dalam industri klinik hewan.

\subsection{Kualitas layanan}

Konsep kualitas layanan menjadi semakin penting dengan meningkatnya persaingan di sektor jasa (Akdere et. al., 2018), namun kualitas layanan tidak mudah didefinisikan dan tergantung sudut pandangnya masing-masing (Ramya et.al., 2019). Kualitas layanan dapat didefinisikan sebagai kemampuan perusahaan untuk memenuhi bahkan melampaui harapan pelanggan (Parasuraman et. al., 1988).

Salah satu cara untuk mencapai keunggulan dalam kompetisi yang ketat, adalah dengan menitikberatkan pada kualitas layanan terhadap pelanggan. Mereka lebih merasakan manfaat dari kualitas layanan, sehingga penting untuk memberikan kualitas layanan terbaik melebihi layanan dari pesaing (Kotler dan Amstrong, 2006).

\subsection{Model SERVPERF untuk kualitas layanan}

Cronin dan Taylor (1992) menawarkan pembenaran teoritis pertama kalinya untuk membuang bagian ekspektasi dari Service Quality (SERVQUAL) kemudian menambahkannya dengan ukuran kinerja 
(Cronin dan Taylor, 1994). Model ini mengembangkan instrument pengukuran berbasis kinerja - disebut, SERVPERF - yang hanya fokus pada persepsi kualitas layanan.

Model SERVPERF mewakili "performance - only measures" (pengukuran kinerja saja) atau pengukuran kualitas layanan yang hanya berfokus pada kinerja organisasi yang dirasakan oleh konsumen dari pada berfokus pada perbedaan antara persepsi kinerja konsumen dengan harapan mereka terhadap kualitas layanan. Variabel-variabel yang masuk dalam SERVPERF adalah responsiveness, empathy, tangible, reliability, assurance (Cronin dan Taylor, 1994).

Lebih jauh lagi, kualitas layanan diukur hanya melalui dimensi persepsi pelanggan dari pada ekspektasi pelanggan. Banyak peneliti memprioritaskan menggunakan SERVPERF dibanding SERVQUAL karena dapat diandalkan dan lebih valid (Dassanayake dan Weerasiri, 2017).

\subsection{Akses untuk mendapatkan layanan}

Akses didefinisikan sebagai hal yang mudah dicapai dan kemudahan untuk dihubungi - layanannya mudah diakses melalui telepon, tidak terlalu lama antri, jam beroperasi yang nyaman, lokasi usaha berada di lokasi yang strategis dan nyaman, serta metode pembayaran (Duong et al., 2004; Miklós et al., 2019).

\subsection{Kepuasan pelanggan}

Kualitas layanan merupakan faktor penting dari kepuasan pelanggan (Rehanam dan Husnain, 2018). Ada hubungan langsung antara kualitas layanan dan kepuasan karena kualitas layanan adalah anteseden kepuasan (Lee et al., 2000). Kepuasan pelanggan didefinisikan sebagai tingkatan di mana kemampuan produk atau layanan yang dapat memenuhi dengan ekspektasi pelanggan (Kotler dan Amstrong, 2006)

\section{Metode Penelitian}

Dalam penelitian ini merupakan penelitian secara kuantitatif, di mana data utama didapat dari hasil survei melalui kuisioner. Penelitian dilakukan melalui kuisioner terhadap 219 pelanggan secara acak yang pernah mengunjungi klinik hewan. Pelanggan harus memenuhi kriteria usia di atas 17 tahun, dapat membaca, menulis dan mengerti bahasa Indonesia, serta bersedia mengisi kuisioner.

Variabel yang digunakan dalam penelitian ini adalah enam variabel independen yang terdiri dari lima variabel dari SERVPERF dan satu variabel independen tambahan dan 1 variabel dependen yaitu kepuasan pelanggan (customer satisfaction). Keenam variabel independen adalah sebagai berikut (Cronin dan Taylor, 1994):

1. Responsiveness: keinginan untuk menolong pelanggan dan memberikan layanan dengan cepat (the willingness to help customers and provide prompt service)

2. Empathy: kepedulian terhadap pelanggan dan memberikan perhatian terhadap pelanggan (caring about others and providing individualized attention to customers).

3. Tangibles: fisik, peralatan dan penampilan karyawan (physical, equipment and appearance of personnel)

4. Reliability: kemampuan untuk melakukan layanan yang dijanjikan secara akurat dan dapat diandalkan (the ability to perform the promised service dependably and accurately).

5. Assurance: pengetahuan dan keramahan karyawan dan kemampuan mereka menciptakan kepercayaan dan keyakinan pelanggan (knowledge and courtesy of employees and their ability to inspire turst and confidence in customers).

6. Access: akses terhadap kemudahan mendapatkan layanan (access to service)

Penelitian ini menganalisis hubungan keenam variabel independen sebagai proksi dari kualitas layanan terhadap satu variabel dependen yaitu kepuasan pelanggan seperti dalam gambar 1 . Keenam variabel independen memiliki 26 (dua puluh enam) pernyataan, dan variabel dependen memiliki 4 (empat) pernyataan. Tabel 1 berikut ini adalah 30 pernyataan kuesioner untuk menilai kinerja kualitas layanan. 


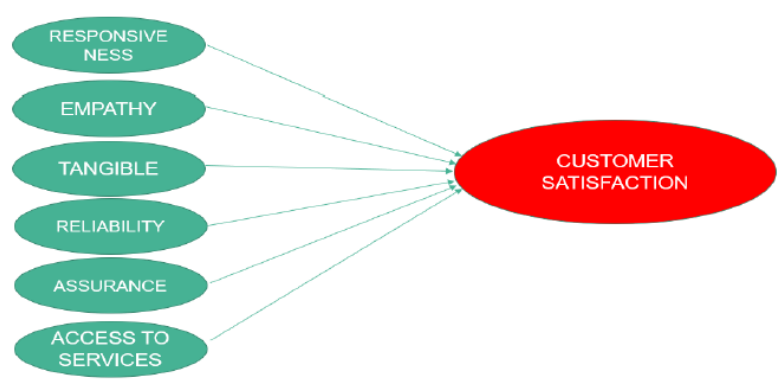

Gambar 1. Model Penelitian

Tabel 1. Daftar item pernyataan kuesioner

\begin{tabular}{|c|c|}
\hline Komponen & Pernyataan \\
\hline $\begin{array}{l}\text { Responsive- } \\
\text { ness }\end{array}$ & $\begin{array}{l}\text { Q1 : Menjelaskan layanan yang akan } \\
\text { dilakukan } \\
\text { Q2 : Memberikan layanan yang cepat } \\
\text { kepada pelanggan } \\
\text { Q3 : Karyawan selalu ingin membantu } \\
\text { pelanggan } \\
\text { Q4 : Karyawan tidak pernah sibuk } \\
\text { untuk menjawab }\end{array}$ \\
\hline Empathy & $\begin{array}{l}\text { Q5 : Perhatian individual pelanggan } \\
\text { Q6 : Jam kerja yang nyaman } \\
\text { Q7 : Perhatian dari karyawn } \\
\text { Q8 : Melayani pelanggan dengan hati } \\
\text { Q9 : Mengerti kebutuhan spesifik } \\
\text { pelanggan }\end{array}$ \\
\hline Tangible & $\begin{array}{l}\text { Q10: Peralatan mutakhir (up-to-date) } \\
\text { Q11 : Fasilitas secara fisik memadai } \\
\text { Q12: Karyawan berpakaian rapi dan } \\
\text { bersih } \\
\text { Q13: Fasilisas fisik konsisten dengan } \\
\text { layanan }\end{array}$ \\
\hline Reliability & $\begin{array}{l}\text { Q14 : Selalu berjanji bekerja tepat } \\
\text { waktu } \\
\text { Q15: Karyawan berlaku simpatik dan } \\
\text { meyakinkan pelanggan } \\
\text { Q16: Melaksanakan layanan tepat } \\
\text { waktu } \\
\text { Q17 : Menjaga dokumen pelanggan } \\
\text { secara akurat } \\
\text { Q18: Dapat diandalkan }\end{array}$ \\
\hline Assurance & $\begin{array}{l}\text { Q19: Pekerja menanamkan rasa } \\
\text { kepercayaan diri } \\
\text { Q20: Aman dalam kegiatan transaksi } \\
\text { Q21 : Karyawan secara konsisten dalam } \\
\text { kesopanan } \\
\text { Q22: Karyawan memilik pengetahuan } \\
\text { atas pertanyaan-pertanyaan }\end{array}$ \\
\hline $\begin{array}{l}\text { Access to } \\
\text { Service }\end{array}$ & $\begin{array}{l}\text { Q23: Layanan dapat dihubungi via } \\
\text { telepon dengan mudah } \\
\text { Q24: Waktu tunggu terhadap informasi } \\
\text { layanan tidak lama } \\
\text { Q25: Akses terhadap beragam metode } \\
\text { pembayaran } \\
\text { Q26: Tempat layanan berada di tempat } \\
\text { yang mudah dijangkau }\end{array}$ \\
\hline $\begin{array}{l}\text { Customer } \\
\text { Satisfaction }\end{array}$ & $\begin{array}{l}\text { Q27 : Memberikan keterangan positif } \\
\text { terhadap layanan klinik hewan kepada }\end{array}$ \\
\hline
\end{tabular}

orang lain

Q28 : Menyarankan teman dan saudara untuk menggunakan jasa layanan klinik hewan

Q29: Intend to continue using the services of this vet clinic

Q30 : Punya rekomendasi kuat untuk klinik hewan

Profil responden dalam penelitian ini dapat dilihat dalam tabel 2.

Tabel 2. Profil Responden

\begin{tabular}{lc}
\hline Profil & Persentase (\%) \\
\hline Jenis Kelamin & \\
- Perempuan & $48,30 \%$ \\
- Laki-Laki & $51,70 \%$ \\
Status & \\
- Menikah (Married) & $21,20 \%$ \\
- Belum Menikah & $76,40 \%$ \\
- Lain-Lain & $2,40 \%$ \\
Umur & \\
- < 17 tahun & $1,00 \%$ \\
- 17 - 40 tahun & $55,70 \%$ \\
- > 40 tahun & $43,30 \%$ \\
Pekerjaan & \\
- Pekerja Karyawan & $65,00 \%$ \\
- Pengusaha & $18,20 \%$ \\
- Tidak bekerja & $8,00 \%$ \\
- Lainnya & $8,90 \%$ \\
\hline
\end{tabular}

Skala Likert memiliki 7 (tujuh) tingkatan di mana skala 7 adalah sangat setuju sekali dan 1 adalah sangat tidak setuju sekali. Responden merupakan para pelanggan dari klinik hewan. Data dikumpulkan dengan menyebarkan kuisioner baik melalui media online maupun tidak online. Hipotesis dirumuskan dalam formulasi sebagai berikut:

Kepuasan Pelanggan $(\mathrm{CS})=\boldsymbol{\beta}_{1} * \mathrm{X}_{1}+\boldsymbol{\beta}_{2} * \mathrm{X}_{2}$ $+\beta_{3} * \mathbf{X}_{3}+\beta_{4} * \mathbf{X}_{4}+\beta_{5} * \mathbf{X}_{5}+\beta_{6} * \mathbf{X}_{6}$

Keterangan:

$\mathrm{X}_{1}=$ Responsiveness,$\quad \mathrm{X}_{2}=$ Empathy,

$\mathrm{X}_{3}=$ Tangibles,

$\mathrm{X}_{4}=$ Reliability,

$\mathrm{X}_{5}=$ Assurance,

$\mathrm{X}_{6}=$ Access

\section{Hipotesis Penelitian}

Penelitian ini memiliki hipotesis tentang hubungan positif antara masing-masing independent variable terhadap kepuasan pelanggan dengan penjelasan hipotesis sebagai berikut: 
- Hipotesis 1 (H1): Terdapat hubungan positif antara Responsiveness terhadap Kepuasan Pelanggan

- Hipotesis 2 (H2): Terdapat hubungan positif antara Empathy terhadap Kepuasan Pelanggan

- Hipotesis 3 (H3): Terdapat hubungan positif antara Tangible terhadap Kepuasan Pelanggan

- Hipotesis 4 (H4): Terdapat hubungan positif antara Reliability terhadap Kepuasan Pelanggan

- Hipotesis 5 (H5): Terdapat hubungan positif antara Assurance terhadap Kepuasan Pelanggan

- Hipotesis 6 (H6): Terdapat hubungan positif antara Access terhadap Kepuasan Pelanggan

\section{Hasil Penelitian dan Pembahasan}

Data survey yang diperoleh dari 219 pelanggan secara acak yang pernah mengunjungi klinik hewan. Pelanggan harus memenuhi kriteria usia di atas 17 tahun, dapat membaca, menulis dan mengerti bahasa Indonesia, serta bersedia mengisi kuisioner. Analisis menggunakan Principal Component Analysis (PCA), pengujian Cronbach's Alpha, dan perhitungan Simple Linear Regression (SLR) dengan dibantu oleh piranti lunak SPSS.

Dari hasil yang kita ambil dari data kuisioner, berikut adalah profil dari para responden. Di bagian ini ditampilkan analisis statistic dan interpretasi, termasuk exploratory factor analysis, definisi variable, dan perhitungan melalui regresi linier. Expolratory factor analysis dilakukan dengan menguji Kaiser-Meyer-Olkin (KMO) untuk menghitung kecukupan sampling seperti dalam tabel 3 .

Tabel 3. Pengujian Kaiser-Meyer-Olkin (KMO) dan Eigen values untuk masing-masing komponen

\begin{tabular}{lcc}
\hline Komponen & KMO & Eigen Values \\
\hline Responsiveness & 0,796 & 2,908 \\
Empathy & 0,871 & 3,678 \\
Tangible & 0,794 & 2,765 \\
Reliability & 0,875 & 3,529 \\
Assurance & 0,826 & 3,051 \\
Access & 0,736 & 2,466 \\
\hline
\end{tabular}

Indeks KMO untuk independent variable adalah dari 0.736 sampai dengan 0.875 dan kepuasan pelanggan 0.868 . Nilai ini dapat diterima dan ukuran sampling sudah mencukupi untuk analisis lanjutan.

Factor loadings di atas 0.5 dan nilai Eigen values sudah lebih dari 1 (Kaiser, 1960), Scree Test (Catell, 1966), varian dari matriks sudah di atas $60 \%$. Masing masing konstruksi independent variable dilakukan PCA masingmasing per konstruksi dengan hasil dalam tabel 4 dan tabel 5.

Tabel 4. Total Variance Explained by Extraction

\begin{tabular}{clrcc}
\hline \multirow{2}{*}{ No } & \multirow{2}{*}{ Dimensi } & \multicolumn{3}{c}{ Initial Eigen Values } \\
\cline { 3 - 5 } & & Total & \% Variance & \% Cumm. \\
\hline 1 & Responsiveness & 2,908 & 72,706 & 72,706 \\
2 & Empathy & 3,678 & 73,562 & 73,562 \\
3 & Tangible & 2,765 & 69,130 & 69,130 \\
4 & Reliability & 3,529 & 70,585 & 70,585 \\
5 & Assurance & 3,051 & 76,274 & 76,274 \\
6 & Access & 2,466 & 61,649 & 61,649 \\
7 & Customer & 3,487 & 87,175 & 87,175 \\
& Satisfaction & 3,45 & & \\
\hline
\end{tabular}

Tabel 4. Total Variance Explained by Extraction (continued)

\begin{tabular}{llccc}
\hline \multirow{2}{*}{ No } & \multirow{2}{*}{ Dimensi } & \multicolumn{3}{c}{ Extraction Sums of Squared } \\
& & Total & \% Variance & \% Cumm. \\
\cline { 3 - 5 } & & 2,908 & 72,706 & 72,706 \\
\hline 1 & Responsiveness & 3,678 & 73,562 & 73,562 \\
2 & Empathy & 2,765 & 69,130 & 69,130 \\
3 & Tangible & 3,529 & 70,585 & 70,585 \\
4 & Reliability & 3,051 & 76,274 & 76,274 \\
5 & Assurance & 2,466 & 61,649 & 61,649 \\
6 & Access & $2,4,175$ & 87,175 \\
7 & Customer & 3,487 & 87,175 \\
& Satisfaction & & & \\
\hline
\end{tabular}

Tabel 5. Factor Loadings

\begin{tabular}{lcc}
\hline Komponen & Pernyataan & Loading \\
\hline \multirow{5}{*}{ Responsiveness } & Q1 & 0,822 \\
& Q2 & 0,885 \\
& Q3 & 0,849 \\
& Q4 & 0,854 \\
\hline \multirow{5}{*}{ Empathy } & Q5 & 0,801 \\
& Q6 & 0,767 \\
& Q7 & 0,901 \\
& Q8 & 0,912 \\
Tangible & Q9 & 0,897 \\
& Q10 & 0,801 \\
& Q11 & 0,795 \\
Reliability & Q12 & 0,842 \\
& Q13 & 0,885 \\
\hline \multirow{4}{*}{} & Q14 & 0,855 \\
& Q15 & 0,878 \\
& Q16 & 0,867
\end{tabular}




\begin{tabular}{lcc}
\hline Komponen & Pernyataan & Loading \\
\hline & Q17 & 0,786 \\
& Q18 & 0,810 \\
\hline \multirow{4}{*}{ Assurance } & Q19 & 0,908 \\
& Q20 & 0,897 \\
& Q21 & 0,895 \\
& Q22 & 0,787 \\
\hline \multirow{4}{*}{ Access to Service } & Q23 & 0,867 \\
& Q24 & 0,772 \\
& Q25 & 0,757 \\
Customer & Q26 & 0,738 \\
Satisfaction & Q27 & 0,940 \\
& Q28 & 0,944 \\
& Q29 & 0,913 \\
& Q30 & 0,938 \\
\hline
\end{tabular}

Pengujian Reliability digunakan dengan menguji Cronbach's alpha di tabel 6 yaitu untuk mengukur konsistensi internal dari masing-masing konstruksi. Sesuai Nunnally (1978), Cronbach's alpha di atas 0.7 dapat diterima. Penelitan ini mendapatkan nilai rentang dari 0.790 to 0.974 , sehingga data pengujian dapat diterima.

Tabel 6. Analisis Cronbach's alpha

\begin{tabular}{lc}
\hline \multicolumn{1}{c}{ Dimension } & Cronbach's alpha \\
\hline Responsiveness & 0,974 \\
Empathy & 0,908 \\
Tangible & 0,849 \\
Reliability & 0,893 \\
Assurance & 0,889 \\
Access & 0,790 \\
Customer Satisfaction & 0,951 \\
\hline
\end{tabular}

\section{Analisis dengan Simple Linear Regression}

Hipotesis dari yang kita buat, dapat dilihat ada hubungan positif antara keenam independent variable terhadap kepuasan pelanggan seperti yang ditampilkan dalam tabel 7 .

Tabel 7. Hasil Uji Model

\begin{tabular}{cccc}
\hline $\mathbf{R}$ & R Square & $\begin{array}{c}\text { Adjusted R } \\
\text { Square }\end{array}$ & $\begin{array}{c}\text { Std Error of } \\
\text { Estimates }\end{array}$ \\
\hline 0,82 & 0,672 & 0,663 & 0,46751 \\
\hline
\end{tabular}

Dapat dilihat bahwa nilai Adjusted $\mathrm{R}$ Square untuk model ini 0,663 dan ANOVA dapat dilihat di tabel 8 di bawah ini $(\mathrm{p}<0.05)$.
Tabel 8. Analysis of Variance (ANOVA)

\begin{tabular}{lccccc} 
Model 1 & $\begin{array}{c}\text { Sum of } \\
\text { Square }\end{array}$ & $\mathbf{d F}$ & $\begin{array}{c}\text { Mean } \\
\text { Squares }\end{array}$ & F & Sig \\
\hline Regression & 94,915 & 6 & 15,819 & 72,378 & 0.00 \\
Residual & 46,336 & 212 & 0,219 & & \\
Total & 141,251 & 218 & & & \\
\hline
\end{tabular}

Tabel 9 adalah penjelasan tentang koefisien ( $\beta$ ) dari keenam independent variable terhadap kepuasan pelanggan.

Tabel 9. Hasil Uji Koefisien ( $\beta$ ) Regresi

\begin{tabular}{lcccc}
\hline \multirow{2}{*}{ Component } & \multicolumn{2}{c}{$\begin{array}{c}\text { Unstandardized } \\
\text { Coefficient }\end{array}$} & T & Sig. \\
\cline { 2 - 3 } & B & Std Error & & \\
\hline Responsiveness & 0,147 & 0,081 & 1.805 & 0,072 \\
Empathy & 0,106 & 0,098 & 1.111 & 0,268 \\
Tangible & 0,133 & 0,069 & 1,913 & 0,057 \\
Reliability & 0,297 & 0,086 & 3,33 & 0,001 \\
Assurance & 0,224 & 0,107 & 2,101 & 0,037 \\
Access & 0,213 & 0,069 & 3,082 & 0,002 \\
\hline
\end{tabular}

Dari hasil kajian survey dan statistic melalui pengolahan dengan SPSS, terdapat hasil hubungan positif antara keenam independent variable dari kualitas layanan terhadap kepuasan pelangan disajikan dalam formulasi di bawah ini:

Kepuasan Pelanggan (CS) $=\beta_{1} * \mathrm{X}_{1}+\beta_{2} * \mathrm{X}_{2}+$ $\beta_{3} * X_{3}+\beta_{4} * X_{4}+\beta_{5} * X_{5}+\beta_{6} * X_{6}$

Maka:

Kepuasan Pelanggan $(\mathrm{CS})=(0,134 *$ Responsiveness $)+(0,097 *$ Empathy $)+$ $(0,108 *$ Tangible $)+(0,235 *$ Reliability $)+$ $(0,206 *$ Assurance $)+(0,196 *$ Access $)$

Diskusi memberikan suatu korelasi besarnya pengaruh reliability dan assurance sebagai indicator terbesar pertama dan kedua dari keempat faktor lainnya dari sisi pemilik hewan peliharaan. Model empiris tervalidasi dapat dilihat dalam gambar 2 . 


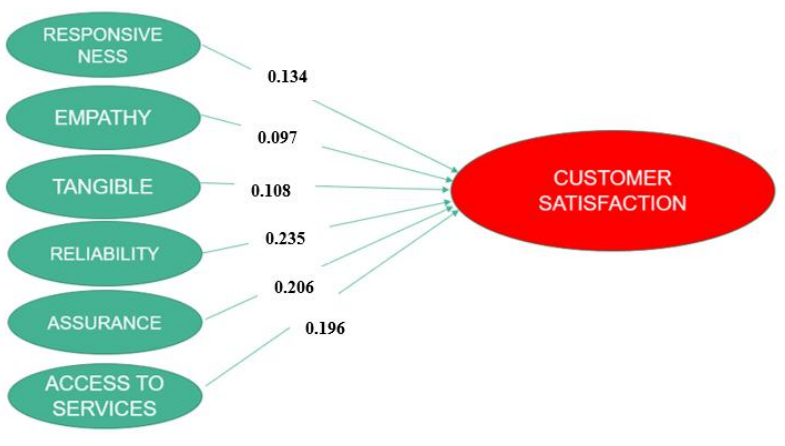

Gambar 2. Model Empiris Tervalidasi

\section{Kesimpulan}

Dari penelitian ini dapat dilihat bahwa semua variabel independen memiliki hubungan positif terhadap variabel dependen. Reliability dan Assurance memiliki pengaruh yang paling besar dari variabel independen yang lain. Penambahan satu variabel independen yaitu Access dalam persepsi tentang kualitas menunjukan hubungan yang positif terhadap variabel dependen dan cukup signifikan pengaruhnya. Untuk meningkatkan kepuasan pelanggan, maka klinik hewan sebaiknya memberikan perhatian yang lebih terhadap aspek Reliability dan Assurance.

Atas perkembangan teknologi saat ini, maka perlu penelitian pengaruh pemanfaatan media sosial terhadap kepuasan pelanggan. Penelitian lanjutan perlu dilakukan di masingmasing daerah untuk melihat karakteristik kepuasan pelanggan yang lebih spesifik.

\section{Daftar Pustaka}

Akdere, M., Top, M., dan Tekingündüz, S. (2018). Examining patient perceptions of service quality in Turkish hospitals : The SERVPERF model. Total Quality Management and Business Excellence, 31(1), pp. 1-11.

Badan Pusat Statistik. (2020). Hasil Sensus Penduduk 2020. Tersedia di https://www.bps.go.id/pressrelease/2021/ 01/21/1854/hasil-sensus-penduduk2020.html

Bates, J.E.G., dan Hoffman, D. (1999). Managing services marketing: Text and readings. Orlando: The Dryden Press Harcourt Brace College Publisher.

Cronin, J.J., dan Taylor, S.A. (1992). Measuring service quality: A re- examination and extension. Journal of Marketing, 56, 55-58.

Cronin, J.J., dan Taylor, S.A. (1994). SERVPERF versus SERVQUAL: Reconciling performance-based and perceptions - minus - expectations measurement of service quality. Journal of Marketing, 58, pp. 125-131.

Dassanayake, P.S., dan Weerasiri, R.A.S. (2017). The Impact of Perceived Service Quality on Customer Satisfaction in Sri Lankan Veterinary Hospital. Singapore Management Journal Vol. 6, No.1, pp. 83-87.

Duong, D.V., Binns, C.W., Lee, A.H., dan Hipgrave, D.B. (2004). Measuring clientperceived quality of maternity services in rural Vietnam. International Journal for Quality in Healthcare Vol.16, No.6, pp. 447-452.

Internet explorer : http://jakartadoglovers.com. Kotler, P., dan Amstrong, G. (2006). Principles of Marketing. 11th ed, New Jersey, Pearson Prentice Hall.

Lee, H., Lee, Y., dan Yoo, D. (2000). The determinants of perceived service quality and its relationship with satisfaction. Journal of Service Marketing, 14(3), pp. 217-231.

Miklós, P., Haddad, H., Nagy, J., dan Popp, J. (2019). The Service Quality Dimensions that Affect Customer Satisfaction in the Jordanian Banking Sector. Sustainability 11(4).

Parasuraman, A.P, Zeithaml, V.A., dan Berry, L.L. (1988). SERVQUAL: A multipleitem scale for measuring consumer perceptions of service quality. Journal of Retailing, 64 (1), pp. 12-40.

Ramya, N., Kowsalya, A., dan Dharanipriya, K. (2019). Services quality and its dimensions. EPRA International Journal of Research and Development (IJRD), 4(2), 38-41.

Rasyida, D.R., Ulkhaq, M.M., Setiowati, P.R., dan Setyorini, N.A. (2016). Assessing Service Quality: A Combination of SERVPERF and Importance-Performance Analysis. MATEC Web of Conferences 68: 06003.

Rehanam, B., dan Husnain, M. (2018). The Impact of Service Quality Dimensions on 
Patient Satisfaction in the Private Healthcare Industry in Pakistan. Journal of Hospital and Medical Management, 4 (1:4), 2.

World Bank, (2019). Indonesia Economic Quarterly Reports (IEQ). page 10 https://www.worldbank.org/en/country/in donesia/publication /indonesia-economicquarterly-reports)

Zeithaml, V.A., Bitner, M.J., dan Gremler, D.D. (2009). Services Marketing: Integrating Customer Focus Across The Firm. (5 th ed). New York: McGraw-Hill. 